This document is confidential and is proprietary to the American Chemical Society and its authors. Do not copy or disclose without written permission. If you have received this item in error, notify the sender and delete all copies.

\title{
Dewar Benzenoids Discovered In Carbon Nanobelts
}

\begin{tabular}{|r|l|}
\hline Journal: & The Journal of Physical Chemistry Letters \\
\hline Manuscript ID & jz-2020-01027r.R2 \\
\hline Manuscript Type: & Letter \\
\hline Date Submitted by the & 21 -Apr-2020 \\
\hline Complete List of Authors: & $\begin{array}{l}\text { Hanson-Heine, Magnus; Nottingham, Chemistry } \\
\text { Rogers, David; University of Nottingham } \\
\text { Woodward, Simon; University of Nottingham, School of Chemistry } \\
\text { Hirst, Jonathan; University of Nottingham, School of Chemistry }\end{array}$ \\
\hline
\end{tabular}

\section{SCHOLARONE" Manuscripts}




\title{
Dewar Benzenoids Discovered In Carbon Nanobelts \\ Magnus W. D. Hanson-Heine, ${ }^{*}$ David M. Rogers, Simon Woodward, and Jonathan D. Hirst \\ School of Chemistry, University of Nottingham, University Park, Nottingham NG7 2RD. \\ *magnus.hansonheine@nottingham.ac.uk
}

\begin{abstract}
The synthesis of cyclacene nanobelts remains an elusive goal dating back over 60 years. These molecules represent the last unsynthesized building block of carbon nanotubes and may be useful both as seed molecules for the preparation of structurally well-defined carbon nanotubes and for understanding the behaviour and formation of zigzag nanotubes more broadly. Here we report the discovery that isomers containing two Dewar benzenoid rings are the preferred form for several sizes of cyclacene. The predicted lower polyradical character and higher singlettriplet stability that these isomers possess compared with their pure benzenoid counterparts suggests that they may be more stable synthetic targets than the structures which have previously been identified. Our findings should facilitate the exploration of new routes to cyclacene synthesis through Dewar benzene chemistry.
\end{abstract}

\section{TOC Graphic}
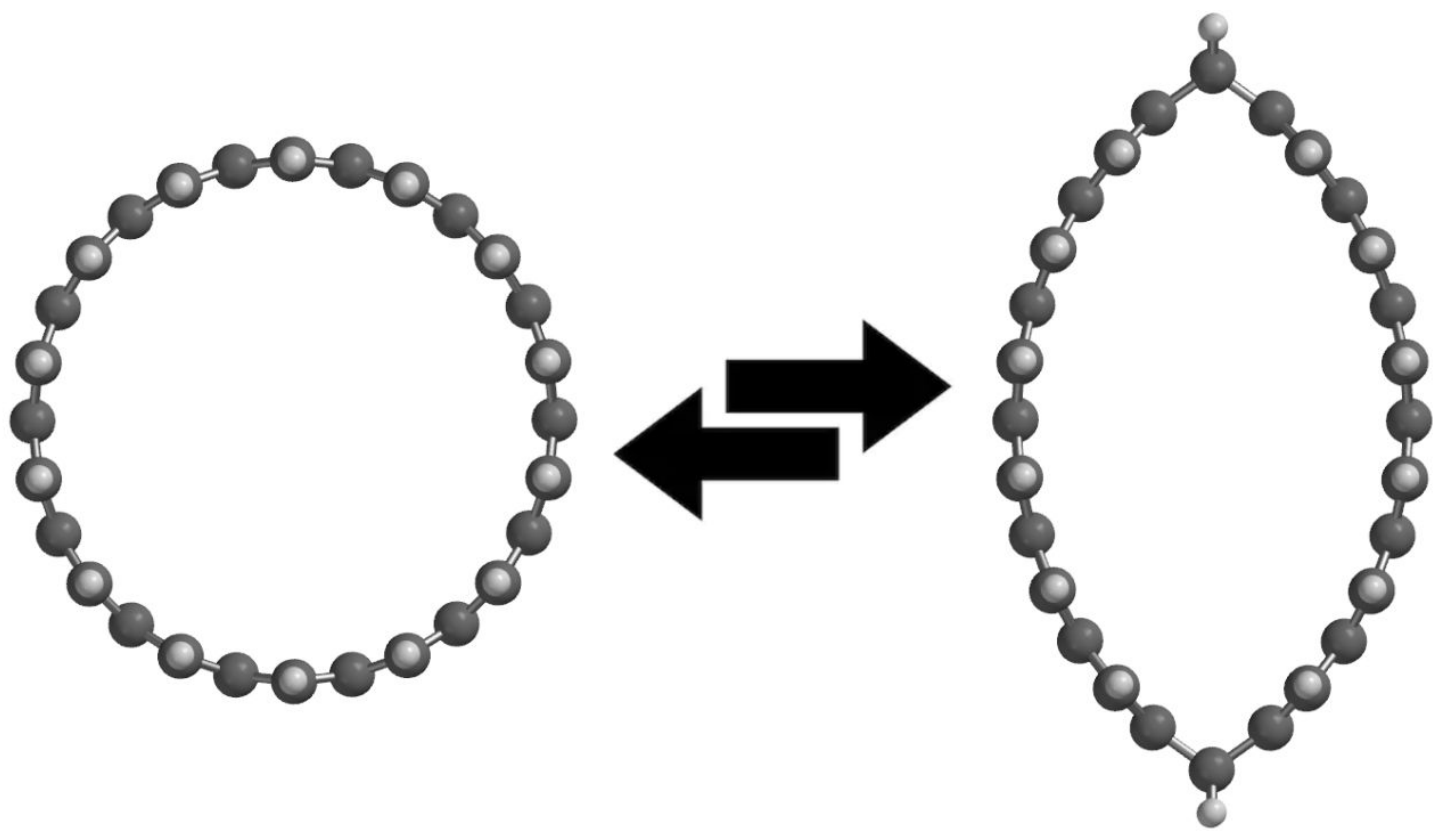
Since their conception by Heilbronner in $1954,{ }^{1}$ cyclacenes have been the focus of extensive ongoing attempts at both synthesis and theoretical characterization. ${ }^{2}$ In their own right, cyclacenes are interesting highly aromatic molecules. They can be considered as having two different types of m-electron system, one comprising an arenoid belt made up of fused benzene rings and the other consisting of two peripheral circuits formed from two fused trans-polyene ribbons called trannulenes. ${ }^{3}$ These trannulene-like circuits show different electronic behaviour for cyclacenes made up of even or odd numbers of fused rings, where the number of $\pi$-electrons in the peripheral circuits becomes $4 k$ or $4 k+2$, with $k$ being a whole number. ${ }^{4}$ These electronic differences are known as cryptoannulenic effects and are responsible for cyclacenes with an even number of fused rings being more stable than those with an odd number. ${ }^{4}$

Cyclacenes are the shortest possible hydrogen-capped zigzag carbon nanotubes and are the last minimal building block of carbon nanotubes that have yet to be synthesized. Understanding the behaviour of cyclacenes can provide important insight into the chemical and mechanical properties of zigzag carbon nanotubes. For example, cyclacenes have been used as a finite-length model for nanotubes in theoretical simulations. ${ }^{5,6}$ If cyclacenes can be synthesized, they also hold promise for acting as templates in the "bottom-up" synthesis of zigzag carbon nanotubes at lowered temperatures due to the potential for early structural diversification and functionalization compared to traditional carbon nanotube approaches. ${ }^{7}$

Despite the sustained interest, all attempts at making cyclacenes have so far been unsuccessful. Pioneering work by Stoddart and co-workers in the 1980s arrived at a hydrogenated derivative, for which dehydrogenation failed to yield the 12-cyclacene product. $^{8-10}$ Cory et al. tried to synthesize 8-cyclacene by a stereospecific double Diels-Alder macroannulation. ${ }^{11}$ Many other approaches have also all ended unsuccessfully. More recently, in 2017 efforts to make armchair and chiral nanobelts culminated in the first successful synthesis of Itami's chiral nanobelt by Povie et al. ${ }^{12}$ In the past year Schulz et al. attempted to make a cyclacene via the formation of tetraepoxycyclacenes on a copper surface. ${ }^{13}$ However, once again the targeted cyclacene products were not detected. Potential explanations for the lack of synthetic success include the high strain that cyclacenes are expected to have, as 
well as predictions of low energy triplet electronic states and significant polyradical character in the ground states. ${ }^{14-16}$

Unusual bonding arrangements, perhaps most famously exemplified by the StoneWales defect, ${ }^{17}$ have important consequences in carbon nanotubes. Herein, we will see that a different type of defect features in certain cyclacenes. Isolated benzene rings have several ring isomers which can undergo isomerization into the more thermodynamically stable standard aromatic structure. ${ }^{18-21}$ Among the isomers of benzene, bicyclo[2.2.0]-hexa-2,5-diene (“Dewar benzene”) becomes more stable when the peripheral hydrogen atoms are substituted by electron-withdrawing groups, ${ }^{22-24}$ or when conjugated with ferrocene. ${ }^{25}$ Dewar benzene may, therefore, also form a long-lived isomer when embedded within a cyclacene. As Dewar benzene is neither flat nor aromatic, due to the carbon atoms at the intersection of the two internal four-membered rings being bound to four atoms in a distorted tetrahedral geometry, the presence of a Dewar benzenoid in a cyclacene can be expected to reduce the ring strain in the remaining benzenoid rings while also disrupting the delocalized aryl and trannulene m-electron circuits, leading to significant changes in the electronic properties. Cyclacene isomers containing Dewar benzenoids have not hitherto been considered in the literature and their properties are the focus of this present study.

To determine their relative stabilities, geometry, vibrational frequency, and energy calculations were performed on the $n$-cyclacene isomers ( $n=5-14$ ) with zero, one, and two Dewar benzenoids, as depicted in Figure. 1 for a 14cyclacene exemplar. The results were calculated using density functional theory (DFT) and confirmed using complete active space self-consistent field theory (CASSCF) and second-order $n$-electron valence perturbation theory (NEVPT2) for a selection of the smaller ring sizes (see Supporting Information for details). In principle one could also consider the free energy using a thermodynamic entropy term derived from the cyclacene vibrational frequencies. However, this would involve a significantly lower level of theory and is expected to provide limited additional insight beyond the primary energetic considerations presented. The different positions that two Dewar benzenoid rings can occupy relative to each other in a cyclacene give structures with different energies. For the 7-cyclacene and 8-cyclacene 
isomers it transpires that the energy is minimized when the distance between the two Dewar benzenoids reaches a maximum (see Supplementary Information). The rest of these calculations have therefore been performed with the two Dewar benzenoid rings located on opposite sides of the molecule. The relative energies calculated for the isomers show that, for the $n$ cyclacenes where $n=5-7$, the isomers with two Dewar benzenoids are the most stable form, and that the single Dewar benzenoid isomer is also more stable than the purely benzenoid isomer for 5-cyclacene.

a
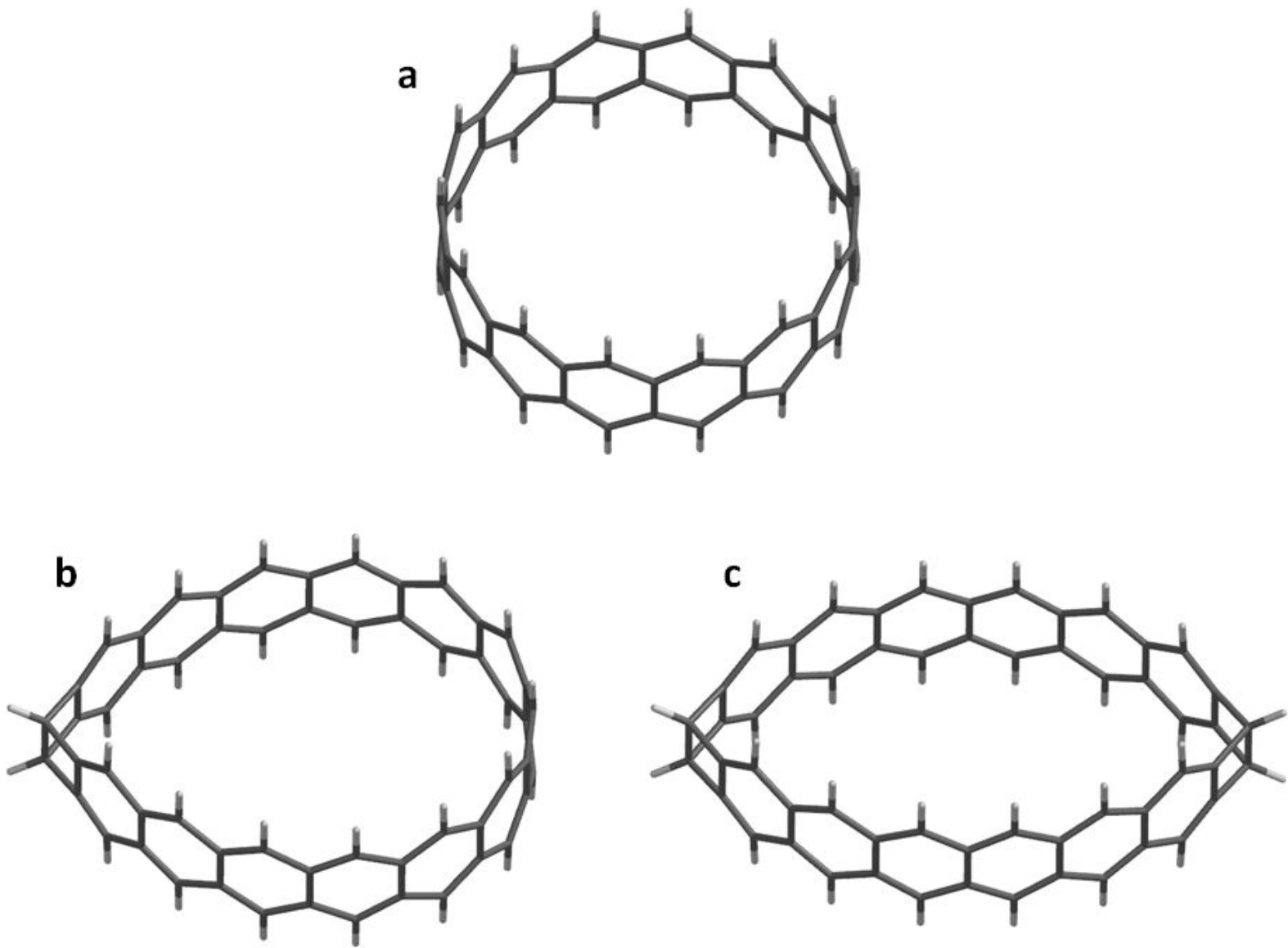

Figure. 1 Optimized geometries of the 14-cyclacene isomers for (a) the isomer containing benzenoid rings only, (b) the isomer containing one Dewar benzenoid ring, and (c) the isomer containing two Dewar benzenoid rings.

These results are shown for DFT in Figure. 2 and validated by the CASSCF and NEVPT2 calculations which can be found together with the tabulated DFT energies in the Supplementary Information. The 5-cyclacene isomer with two Dewar benzenoids is predicted to be ca. $85.0 \mathrm{kcal} / \mathrm{mol}$ below the standard isomer when using NEVPT2 and the single Dewar benzenoid isomer is 
predicted to be $38.4 \mathrm{kcal} / \mathrm{mol}$ below the conventional isomer. The cyclacene isomers with no Dewar benzenoids are the most stable form at ring sizes of $n$ $=8$ and larger. The isomers containing a single Dewar benzenoid become more stable than the isomers containing two Dewar benzenoids after the 9cyclacene ring size. As the newly identified isomers are more stable than the conventional cyclacenes for smaller ring sizes, they provide new intermediate targets for synthesis and are likely to play an important role in understanding the behaviour of cyclacene systems during synthesis and isolation. The geometries calculated for the pure benzenoid isomers in this work closely match those reported in the literature. ${ }^{15}$, 16, 43 Cartesian coordinates for the isomers studied have been provided in the Supplementary Information together with discussion of some of the newly identified key structural features.

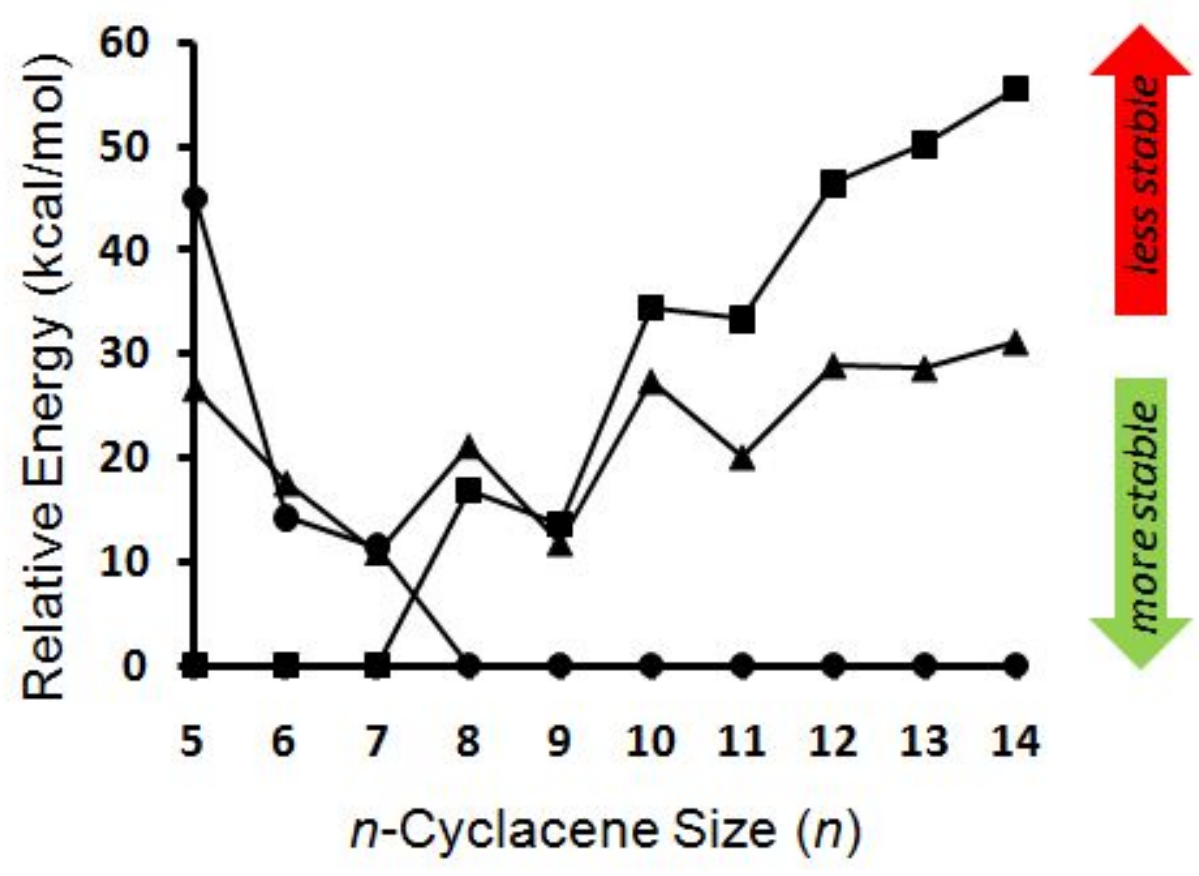

Figure. 2 Relative energies of the n-cyclacene isomers calculated using TAO-DFT where the number of Dewar benzenoids is zero (circles), one (triangles), or two (squares).

One proposal to explain why cyclacene synthesis has proven to be such a hard problem is because of their unique electronic properties. Conventional cyclacene isomers are predicted to have readily accessible excited electronic states, and significant polyradical character in their singlet ground state configurations that anti-correlates strongly with their singlet-triplet energy gaps. ${ }^{16}$ Radical indices have been calculated at between 1 and 2 unpaired 
electrons for the even numbered cyclacenes where $n=6,8$, and 10 , with an increase to between 3 and 4 unpaired electrons when $n=12,14$, and 16 using CASSCF methods. ${ }^{16}$ The cyclacene isomers considered here are all predicted to have singlet ground state configurations, and their singlet-triplet energy gaps are shown in Figure. 3(a). The singlet-triplet energy gaps for the pure benzenoid $n$-cyclacenes oscillate, with the even $n$ species having more stable ground states than the species with odd $n$, due to the presence of cryptoannulenic effects. The ground states for the isomers with one Dewar benzenoid are more stable for the low $n$ ring sizes and do not have oscillating energy gaps. The isomers with two Dewar benzenoids also do not show the oscillating pattern indicative of cryptoannulenic effects and have significantly larger singlet-triplet gaps, starting $1.66 \mathrm{eV}$ above the purely benzenoid isomer for 5-cyclacene. The isomers with two Dewar benzenoids follow a nearly monotonically decreasing trend as the ring size increases. The one notable exception to this trend is the 7-cyclacene isomer, which has an anomalously large singlet-triplet energy gap and increased singlet stability compared with the equivalent 6-cyclacene isomer when calculated using DFT. Because the cyclacene isomers containing two Dewar benzenoids have a comparatively small degree of fractional orbital occupation (vide infa), they can be described more meaningfully using a single set of orbitals than the other isomers. The singlet-triplet energy gaps for these isomers follow a similar trend to the differences between the canonical highest occupied molecular orbital (HOMO) and lowest unoccupied molecular orbital (LUMO) energies when using DFT, and the relative increase in stability of the ground state of the 7-cyclacene isomer can be rationalized as partly due to a $0.24 \mathrm{eV}$ increase in the LUMO energy compared to the corresponding 6-cyclacene isomer. The cavity of the 7-cycalcene isomer is small enough and of sufficiently low-symmetry to allow the LUMO to involve a significant delocalization across the cavity as shown in Figure. 3(b). 


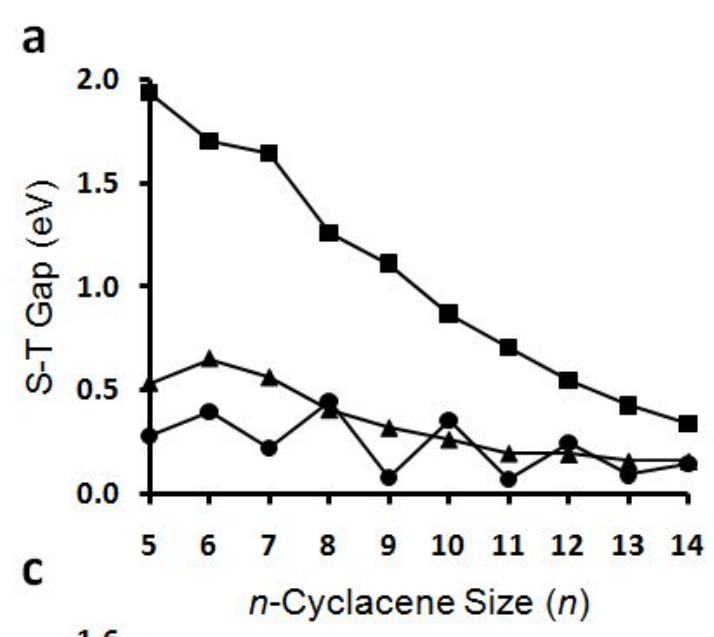

b
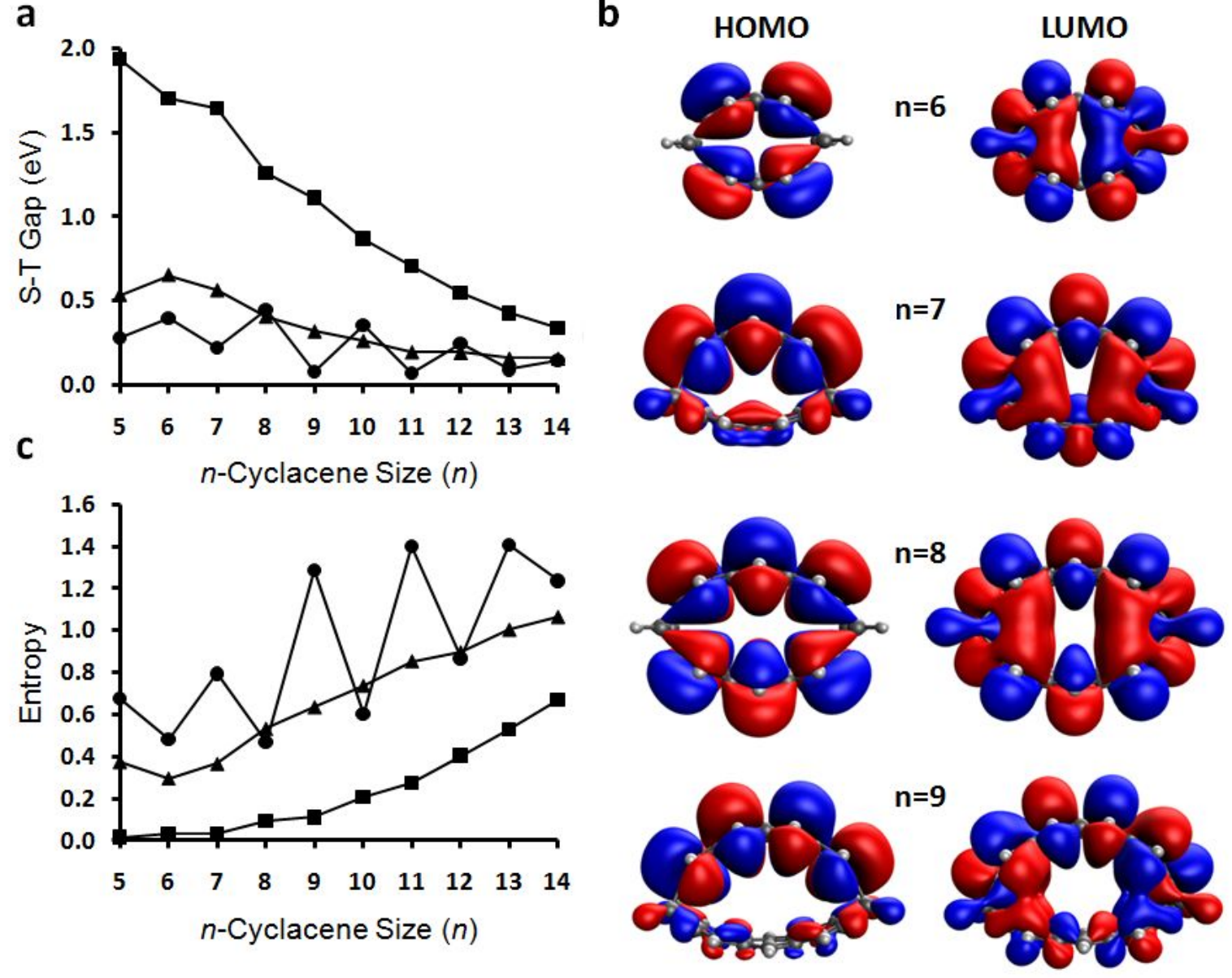

Figure. 3 Electronic properties of Dewar benzenoid containing cyclacenes. (a) the Singlet-triplet vertical transition energies for $n$-cyclacene isomers where the number of Dewar benzenoids is zero (circles), one (triangles), or two (squares). (b) canonical DFT HOMOs and LUMOs for the $n$-cyclacene isomers containing two Dewar benzenoids ( $n=6-9$, shown in descending order) at an isosurface value of $0.02 \mathrm{e} / \AA^{3}$. The HOMO is defined here as the $(N / 2)^{\text {th }}$ orbital and LUMO is defined as the $(N / 2+1)^{\text {th }}$ orbital. (c) symmetrized von Neumann entropy for $n$-cyclacene isomers, where the number of Dewar benzenoids is zero (circles), one (triangles), or two (squares).

Symmetrized von Neumann entropy (see Supporting Information) can be used to estimate the radical character by measuring the degree to which orbitals are fractionally occupied. The radical character thus measured is shown in Figure. 3(c). For the pure cyclacenes the symmetrized von Neumann entropy oscillates in line with previous calculations, attributed to cryptoannulenic effects. ${ }^{26}$ These oscillations indicate that $n$-cyclacenes with odd $n$ have a higher radical character than the even $n$ species, when $n$ is relatively small. The cyclacene isomers with single Dewar benzenoids do not show oscillating 
behaviour, and begin to follow a near linear trend with increasing size from the 8-cyclacene isomers onwards after an initial decrease in the symmetrized von Neumann entropy between the 5-cyclacene and 6-cyclacene isomers. The entropy for these isomers appears to be anti-correlated to the singlet-triplet gaps, suggesting a close relationship between the transition energy and the radical character. In contrast, the isomers containing two Dewar benzenoids have relatively low symmetrized von Neumann entropies and are likely to have very limited radical character and little static electron correlation. Thus, they are likely to be well described by single reference ab initio methods, particularly for values of $n<10$. The symmetrized von Neumann entropies show a different trend to the singlet-triplet gaps at these values of $n$, suggesting that the relative stability of the singlet ground state in these isomers is not due to the presence of radicals. Furthermore, the relative stability that these isomers are predicted to have strongly suggests that they should be synthetically accessible from simple fragments by the generalized synthetic strategies exemplified in Figure S1 of the Supporting Information.

The discovery that cyclacene isomers containing two maximally separated Dewar benzenoids are predicted to be more stable than the purely benzenoid cyclacenes when the ring size is small, together with the lower polyradical character and significantly larger singlet-triplet energy gaps, imply that these systems are much less reactive than the isomers that have previously been considered. These isomers are expected to be metastable with respect to the pure benzenoid cyclacenes for the larger belts and to interconvert for the smaller belt sizes. Their discovery therefore represents a promising set of new synthetic targets for a wide range of nanobelts systems.

\section{ASSOCIATED CONTENT}

\section{Supporting Information}

The Supporting Information is available free of charge at https://pubs.acs.org/doi/... 
Computational details, calculated absolute energies, leading CASSCF configuration weights, Cartesian coordinates, and discussion of the geometric properties for the $n$ cyclacene isomers studied.

\section{AUTHOR INFORMATION \\ Corresponding Author \\ *magnus.hansonheine@nottingham.ac.uk \\ ORCID}

Magnus W. D. Hanson-Heine: 0000-0002-6709-297X

David M. Rogers: 0000-0003-2167-113X

Simon Woodward: 0000-0001-8539-6232

Jonathan D. Hirst: 0000-0002-2726-0983

Notes

The authors declare no competing financial interest.

\section{ACKNOWLEDGEMENTS}

This research was funded by the University of Nottingham Green Chemicals Beacon and by the University of Nottingham Propulsion Futures Beacon. We are grateful for access to the University of Nottingham High Performance Computer.

\section{REFERENCES}

1. Heilbronner, E. Helv. Chim. Acta 1954, 37, (3), 921-935.

2. Tahara, K.; Tobe, Y. Chem. Rev. 2006, 106, (12), 5274-5290.

3. Türker, L.; Gümüş, S. J. Mol. Struct. (Theochem) 2004, 685, (1), 1-33.

4. Türker, L. Polycyclic Aromat. Compd. 1994, 4, (3), 191-197.

5. Irle, S.; Mews, A.; Morokuma, K. J. Phys. Chem. A 2002, 106, (49), 1197311980.

6. Quiñonero, D.; Frontera, A.; Garau, C.; Costa, A.; Ballester, P.; Deyà, P. M. Chem. Phys. Lett. 2005, 411, (1), 256-261.

7. Jasti, R.; Bertozzi, C. R. Chem. Phys. Lett. 2010, 494, (1), 1-7.

8. Kohnke, F. H.; Slawin, A. M. Z.; Stoddart, J. F.; Williams, D. J. Angew. Chem. Int. Ed. 1987, 26, (9), 892-894. 
9. Ashton, P. R.; Isaacs, N. S.; Kohnke, F. H.; Slawin, A. M. Z.; Spencer, C. M.; Stoddart, J. F.; Williams, D. J. Angew. Chem. Int. Ed. 1988, 27, (7), 966-969.

10. Ashton, P. R.; Brown, G. R.; Isaacs, N. S.; Giuffrida, D.; Kohnke, F. H.; Mathias, J. P.; Slawin, A. M. Z.; Smith, D. R.; Stoddart, J. F.; Williams, D. J. J. Am. Chem. Soc. 1992, 114, (16), 6330-6353.

11. Cory, R. M.; McPhail, C. L.; Dikmans, A. J.; Vittal, J. J. Tetrahedron Lett. 1996, 37, (12), 1983-1986.

12. Povie, G.; Segawa, Y.; Nishihara, T.; Miyauchi, Y.; Itami, K. Science 2017, 356, (6334), 172-175.

13. Schulz, F.; García, F.; Kaiser, K.; Pérez, D.; Guitián, E.; Gross, L.; Peña, D. Angew. Chem. Int. Ed. 2019, 58, (27), 9038-9042.

14. Matsui, K.; Fushimi, M.; Segawa, Y.; Itami, K. Org. Lett. 2016, 18, (20), 53525355.

15. Sadowsky, D.; McNeill, K.; Cramer, C. J. Faraday Discuss. 2010, 145, (0), 507-521.

16. Battaglia, S.; Faginas-Lago, N.; Andrae, D.; Evangelisti, S.; Leininger, T. J. Phys. Chem. A 2017, 121, (19), 3746-3756.

17. Stone, A. J.; Wales, D. J. Chem. Phys. Lett. 1986, 128, (5), 501-503.

18. Van Tamelen, E. E.; Pappas, S. P. J. Am. Chem. Soc. 1962, 84, (19), 37893791.

19. Katz, T. J.; Acton, N. J. Am. Chem. Soc. 1973, 95, (8), 2738-2739.

20. Katz, T. J.; Roth, R. J.; Acton, N.; Carnahan, E. J. J. Org. Chem. 1999, 64, (20), 7663-7664.

21. Katz, T. J.; Wang, E. J.; Acton, N. J. Am. Chem. Soc. 1971, 93, (15), 37823783.

22. Schäfer, W. Angew. Chem. 1966, 78, (14), 716-716.

23. Schäfer, W.; Criegee, R.; Askani, R.; Grüner, H. Angew. Chem. 1967, 79, (1), 54-55.

24. Janková, Š.; Dračínský, M.; Císařová, I.; Kotora, M. Eur. J. Org. Chem. 2008, 2008, (1), 47-51.

25. Janková, Š.; Císařová, I.; Uhlík, F.; Štepnička, P.; Kotora, M. Dalton Trans. 2009, (17), 3137-3139.

26. Houk, K. N.; Lee, P. S.; Nendel, M. J. Org. Chem. 2001, 66, (16), 5517-5521.

27. Wu, C.-S.; Lee, P.-Y.; Chai, J.-D. Sci. Rep. 2016, 6, 37249. 
a
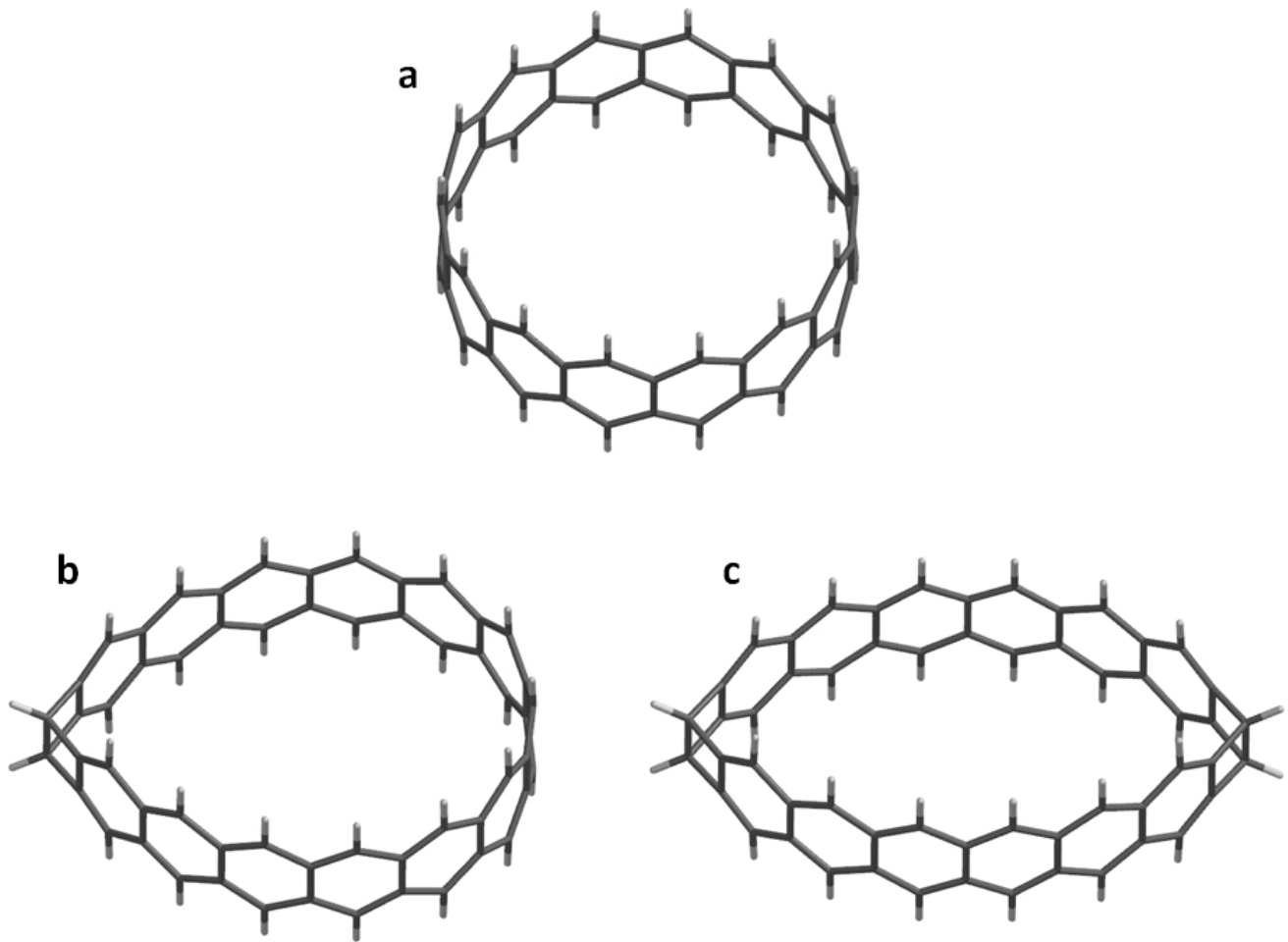

Figure. 1 Optimized geometries of the 14-cyclacene isomers for (a) the isomer containing benzenoid rings only, (b) the isomer containing one Dewar benzenoid ring, and (c) the isomer containing two Dewar benzenoid rings.

$241 \times 177 \mathrm{~mm}(96 \times 96 \mathrm{DPI})$ 
Figure. 2 Relative energies of the n-cyclacene isomers calculated using TAO-DFT where the number of Dewar benzenoids is zero (circles), one (triangles), or two (squares).

\section{$126 \times 92 \mathrm{~mm}(96 \times 96 \mathrm{DPI})$}

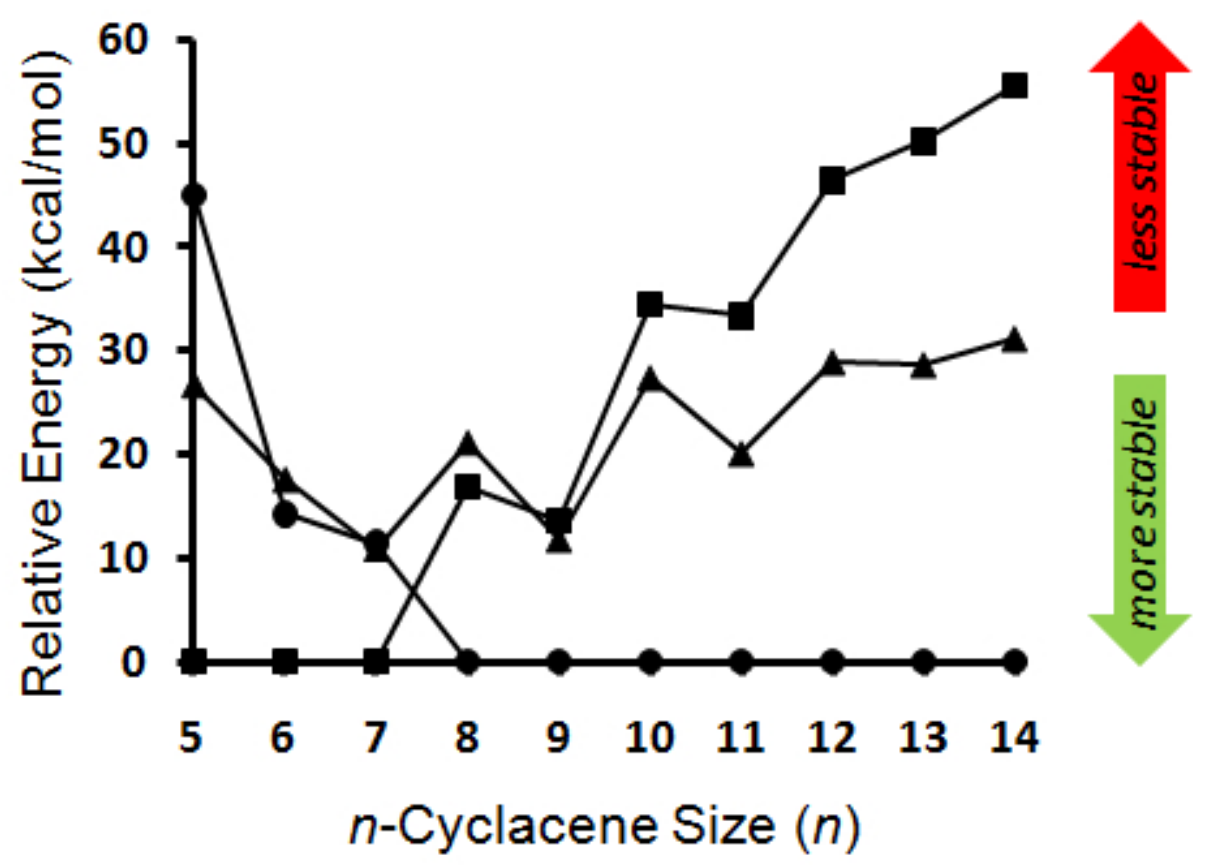


a
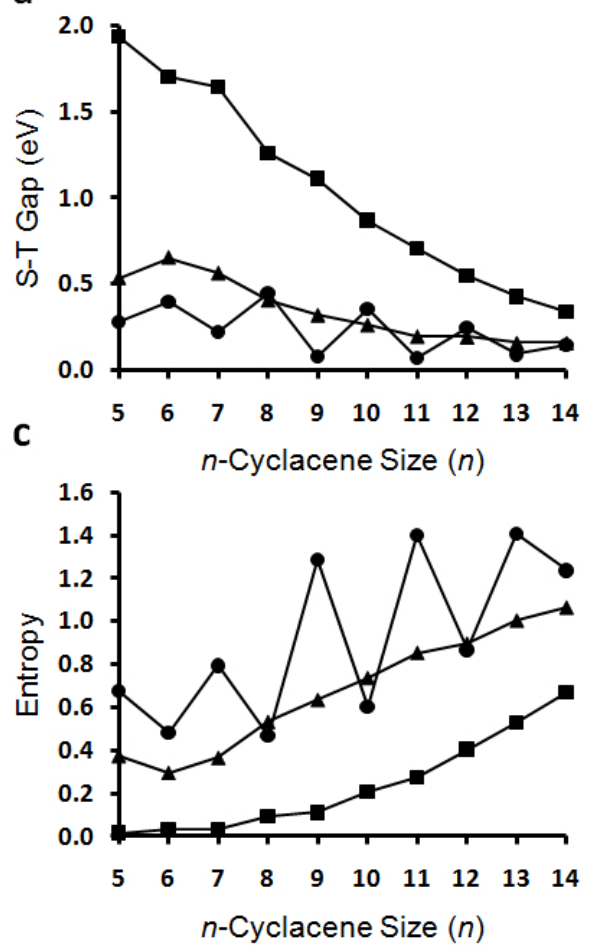

b
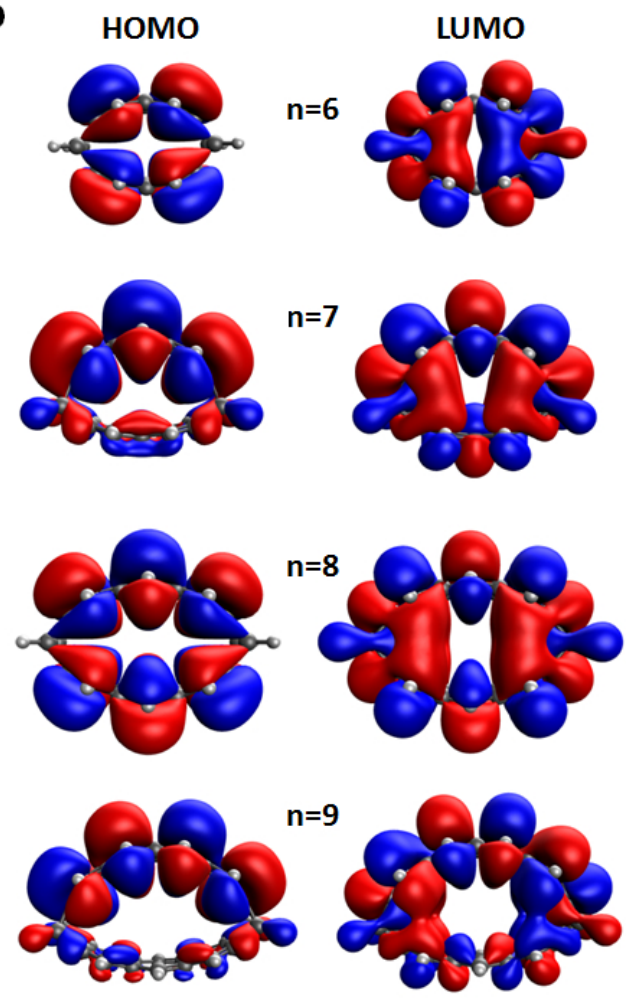

Figure. 3 Electronic properties of Dewar benzenoid containing cyclacenes. (a) the Singlet-triplet vertical transition energies for $n$-cyclacene isomers where the number of Dewar benzenoids is zero (circles), one (triangles), or two (squares). (b) canonical DFT HOMOs and LUMOs for the n-cyclacene isomers containing two Dewar benzenoids ( $n=6-9$, shown in descending order) at an isosurface value of 0.02 e/ $\AA 3$. The HOMO is defined here as the (N/2)th orbital and LUMO is defined as the (N/2+1)th orbital. (c) symmetrized von Neumann entropy for $n$-cyclacene isomers, where the number of Dewar benzenoids is zero (circles), one (triangles), or two (squares).

$239 \times 191 \mathrm{~mm}(96 \times 96 \mathrm{DPI})$ 